\title{
Ossifying Fibromyxoid Tumor
}

National Cancer Institute

\section{Source}

National Cancer Institute. Ossifying Fibromyxoid Tumor. NCI Thesaurus. Code C6582.

A rare soft tissue tumor of uncertain lineage characterized by the presence of neoplastic spindle to round cells forming cords in a fibromyxoid stroma. The lesions are associated with the formation of metaplastic bone. Most patients present with painless subcutaneous masses. Recurrences have been reported in a minority of patients. 